\title{
Implementasi Algoritma ElGamal Dalam Proses Enkripsi dan Dekripsi Untuk Pengamanan Citra Digital Pada Perangkat Mobile
}

\author{
Fachriyan Rizki Ibrahim ${ }^{1}$, Arry Avorizano, M.Kom² \\ ${ }^{1,2)}$ Fakultas Teknik UHAMKA, \\ Jl. Tanah Merdeka No.6, RT.10/RW.3, Jakarta Timur, Telp: 8400941, Mobile: 085813001800 \\ E-mail: fachriyanri@gmail.com ${ }^{1}{ }^{\text {arry.avorizano@ } \text { uhamka.ac.id }^{2}}$
}

\begin{abstract}
Abstrak - Implementasi keamanan data adalah salah satu cara efektif dalam mengamankan data demi melindungi privasi dan keaslian data milik pengguna. Subjek dalam penelitian adalah bagaimana cara melindungi suatu file citra digital. Metode yang digunakan adalah Kriptografi ElGamal, metode tersebut adalah suatu bagiana dari kriptografi asimetris. Terdapat tiga proses didalam Kriptogtafi ElGamal, yaitu proses pembuatan kunci, proses enkripsi data dan proses dekripsi data. Metode yang digunakan pada penelitian ini adalah research dan development $(R \& D)$ yang dimulai dari identifikasi masalah sampai produksi prototipe akhir.

Hasil dari penelitian ini di implementasikan dalam suatu program perangkat lunak pada perangkat Android dengan menggunakan bahasa pemrograman Java yang dapat memberikan kemudahan bagi setiap orang yang ingin mengamankan data - data gambar penting.
\end{abstract}

Kata kunci: ElGamal, Keamanan, Citra Digital, Android, Java.

\section{PENDAHULUAN}

Di era digital saat ini banyaknya ponsel dengan spesifikasi kamera yang mumpuni memudahkan pengguna untuk menyimpan gambar langsung di ponsel, tetapi dengan kemudahan penyimpanan tersebut menimbulkan celah keamanan data gambar oleh orang-orang yang tidak bertanggung jawab melakukan pencurian data gambar pribadi, memanipulasi gambar, dan mengubah isi gambar tanpa izin dari pemilik gambar yang bersangkutan.

Berbagai macam cara menyembunyikan gambar sudah banyak ditemukan salah satu yang paling banyak digunakan adalah dengan cara melakukan hidden, yaitu sebuah teknik penyembunyian file agar tidak dapat terbaca dan terlihat. Perkembangan penyembunyian gambar itu sendiri semakin hari semakin pesat. Dengan kata lain gambar yang disembunyikan tersebut sudah tentu banyak orang yang sudah mengetahui cara untuk membukanya, hal ini membuat beberapa instansi yang memiliki gambar yang bersifat penting dan rahasia merasa bahwa ini sudah tidak aman. Karena dengan hanya melakukan hidden data citra digital asli dapat langsung terbaca dengan melakukan pengaturan show hidden file. Maka dari itu dibutuhkan keamanan tambahan yaitu dengan cara melakukan pengenkripsian data.

Beberapa gambar yang bersifat penting seperti gambar rancangan suatu proyek pembangunan, gambar rangkaian prototipe suatu produk, dan gambar yang bernilai dan bersifat penting lainnya tentu harus dijaga kerahasiaanya agar tidak disalahgunakan oleh pihak luar yang tidak berkepentingan.

Salah satu metode yang dipilih pada penelitian ini adalah metode ElGamal. Dengan metode Algoritma ElGamal ini keamanan data gambar dapat lebih terjaga kerahasiaannya. Karena algoritma ini memiliki kelebihan antara lain terletak pada metode pembentukan kunci yang menggabungkan antara enkripsi kunci publik dan enkripsi kunci privat sehingga tanda tangan digital atau kunci rahasia tersebut tidak dapat di kriptanalis.

Berdasarkan uraian diatas penulis bermaksud mendesain dan merancang suatu aplikasi pada perangkat mobile yang berfungsi untuk mengamankan data gambar sehingga keamanan dan privasi dari pemilik gambar akan lebih terjaga.

\section{LANDASAN TEORI}

Menurut Richard Mollin (2003), Kriptografi (cryptography) berasal dari bahasa Yunani terdiri dari dua silabel yaitu kriptos dan graphia. Kriptos artinya menyembunyikan, sedangkan graphia artinya tulisan. Sedangkan Menurut Menezes, Oorscoot dan Vanstone (1996), kriptografi adalah ilmu yang mempelajari teknik-teknik matematika yang 
berkaitan dengan aspek keamanan informasi, seperti kerahasiaan data, keabsahan data, dan autentikasi data. Tetapi tidak semua aspek keamanan informasi dapat diselesaikan dengan kriptografi. Kriptografi dapat pula diartikan sebagai ilmu untuk melindungi keamanan sandi. ${ }^{[1]}$

Bersumber pada sejumlah pengertian kriptografi di atas, dapat disimpulkan bahwa Kriptografi merupakan ilmu sekaligus seni untuk melindungi keamanan pesan dan informasi agar tidak berhasil dilihat, dibaca, dimengerti oleh pihak ketiga yang tidak memiliki wewenang dan otoritas terhadap data atau informasi tersebut. ${ }^{[1]}$

Kriptanalisis (cryptanalysis) adalah kebalikan dari kriptografi, yaitu suatu ilmu untuk memecahkan mekanisme kriptografi dengan cara mendapatkan kunci dari ciphertext yang digunakan untuk mendapatkan plaintext. Kriptologi (cryptology) adalah ilmu yang menggabungkan antara kriptografi dan kriptanalisis. ${ }^{[1]}$

Algoritma Kriptografi bersumber pada jenis penyandian yang diterapkan dapat dibedakan menjadi dua jenis yaitu :

1. Symmetric Cryptography (Kriptografi Simetri), adalah suatu keadaan saat kunci yang digunakan untuk melakukan teknik enkripsi dan teknik dekripsi adalah kunci yang serupa.

2. Asymmetric Cryptography (Kriptografi Asimetri), adalah suatu keadaan saat kunci yang digunakan untuk melakukan teknik enkripsi dan teknik dekripsi menggunakan kunci yang berlainan. ${ }^{[5]}$

Berdasarkan paparan tersebut dapat disimpulkan bahwa kriptografi asimetri mempunyai tingkat proteksi yang lebih baik dibandingkan kriptografi simetri. Pengirim informasi memakai kunci publik untuk melindungi informasi yang ingin disampaikan, kunci publik dapat diketahui oleh seluruh pihak, tetapi kunci publik tidak dapat digunakan untuk membuka informasi dan pesan. Dekripsi informasi hanya dapat dilakukan dengan memakai kunci privat yang hanya bisa diketahui oleh penerima informasi yang sesungguhnya. ${ }^{[5]}$

Tetapi, Kriptografi Asimetri mempunyai suatu kelemahan yaitu kecepatan yang dimiliki kriptografi asimetri lebih rendah jika dibandingkan kriptografi simetri. Kriptografi Asimetri tidak cocok digunakan untuk melindungi informasi dalam jumlah besar. Dalam implementasinya, pertukaran data di internet, pengiriman email, atau transaksi perbankan secara online menggunakan metode hybrid. Metode hybrid melindungi data asli secara simetris, namun kunci yang digunakan secara asimetris. Metode hybrid ini menggabungkan perpindahan kunci yang aman dan enkripsi yang cepat. ${ }^{[5]}$

Kriptografi tersusun atas dua proses utama yaitu proses enkripsi dan dekripsi. ${ }^{[1]}$

Enkripsi adalah suatu teknik untuk melakukan pergantian suatu kode dari yang biasa dipahami menjadi suatu kode yang tidak dipahami atau sulit dibaca. Dari definisi di atas dapat disimpulkan Enkripsi adalah mengacak suatu kode menjadi kode lain sehingga tidak dapat diketahui kode aslinya. ${ }^{[2]}$

Enkripsi pada komputer dilakukan dengan menggeser bit pada karakter ASCII sebanyak x buah ke kiri atau ke kanan, sehingga kata akan teracak dan tidak dapat dibaca, dalam kriptografi enkripsi merupakan suatu hal yang sangat penting agar keamanan data benar benar terjaga dan bisa dilindungi dengan baik. Pesan asli diubah menjadi suatu kode yang sulit dipahami, enkripsi sendiri bisa diartikan suatu cipher atau kode. Agar dapat mengubah ke bentuk awal dari pesan dibutuhkan suatu algoritma yang dapat digunakan untuk mengubah pesan yang diinginkan. ${ }^{[2]}$

\subsection{Hill Cipher}

Teknik kriptografi ini dibuat agar dapat menciptakan suatu cipher (kode) yang sulit untuk dipecahkan dengan menggunakan metode analisa frekuensi. Teknik ini tidak mengubah masing-masing huruf yang serupa pada plaintext dengan huruf lainnya yang serupa pada chipertext karena memakai perkalian matriks pada pembentukan enkripsi dan dekripsinya. Teknik kriptografi ini ditemukan pertama kali oleh Lester S.Hill pada tahun 1929. ${ }^{[10]}$

Berdasarkan jenis penyandian yang diterapkan, kriptografi Hill Cipher tergolong kedalam Algoritma Simetrik (Symmetric Algorithms), karena algoritma ini memakai suatu kunci yang serupa untuk melakukan prosedur enkripsi dan dekripsi data. Dalam melakukan proses enkripsi dan dekripsi, algoritma ini memakai suatu matriks persegi sebagai kunci yang diterapkan dan menerapkan aritmatika modulo. ${ }^{[10]}$

Dalam proses enkripsi, algoritma ini mengambil plaintext yang berurutan dan setiap huruf diberi nilai berupa angka seperti $\alpha=0 \quad b=1, \ldots, z=25$. Untuk $m=3$, metode persamaan dapat didefinisikan sebagai berikut:

$$
\begin{aligned}
& C_{1}=\left(K_{11} P_{1}+K_{12} P_{2}+K_{13} P_{3}\right) \bmod 26 \\
& C_{2}=\left(K_{21} P_{1}+K_{22} P_{2}+K_{23} P_{3}\right) \bmod 26 \\
& C_{1}=\left(K_{31} P_{1}+K_{32} P_{2}+K_{33} P_{3}\right) \bmod 26
\end{aligned}
$$

Persamaan diatas memakai modulo 26 disebabkan alphabet yang akan dipakai pada saat melakukan enkripsi dan dekripsi sejumlah 26 karakter. Apabila persamaan diatas digunakan untuk citra digital berwarna (8 bit) maka Persamaan (1) memakai modul 256, sehingga Persamaan (1) menjadi :

$$
\begin{aligned}
& C_{1}=\left(K_{11} P_{1}+K_{12} P_{2}+K_{13} P_{3}\right) \bmod 256 \\
& C_{2}=\left(K_{21} P_{1}+K_{22} P_{2}+K_{23} P_{3}\right) \bmod 256 \\
& C_{1}=\left(K_{31} P_{1}+K_{32} P_{2}+K_{33} P_{3}\right) \bmod 256
\end{aligned}
$$

Persamaan (1) tanpa modular dapat diekspresikan dalam bentuk vektor kolom dan matriks sehingga menjadi :

$$
\left(\begin{array}{c}
C_{1} \\
C_{2} \\
C_{3}
\end{array}\right)=\left[\begin{array}{lll}
K_{11} & K_{12} & K_{13} \\
K_{21} & K_{22} & K_{23} \\
K_{31} & K_{32} & K_{33}
\end{array}\right]\left(\begin{array}{c}
P_{1} \\
P_{2} \\
P_{3}
\end{array}\right)
$$


atau sederhananya dapat menulis berupa $\mathrm{C}=\mathrm{KP}$, dimana $\mathrm{P}$ dan $\mathrm{C}$ adalah vektor kolom dengan panjang 3 baris, masing-masing baris mewakili plaintext dan ciphertext, dan $\mathrm{K}$ merupakan matriks $3 \times 3$, yang merupakan matriks kunci pada proses enkripsi. Untuk proses dekripsi memerlukan invers dari matriks $\mathrm{K}$ yang dibuat pada proses enkripsi. Invers matriks $\mathrm{K}(\mathrm{K}-1)$ didefinisikan oleh persamaan $\mathrm{K} * \mathrm{~K}-1=\mathrm{K}-1 * \mathrm{~K}=\mathrm{I}$, dimana I dinyatakan sebagai matriks identitas. Secara umum persaman tersebut dapat didefinisikan sebagai berikut:

Dalam proses Enkripsi:

$$
C=E_{k}(P)=K_{p} P
$$

Dalam proses Dekripsi:

$$
P=D_{k}(C)=K^{-1} C=K^{-1} K_{p}=P
$$

\subsection{Kriptosistem ElGamal}

Algoritma ElGamal dipublikasikan oleh Taher ElGamal pada tahun 1985. Hingga saat ini, algoritma ElGamal masih digunakan sebagai salah satu metode penyandian, contohnya pada penggunaan aplikasi PGP dan GnuPG yang terdapat pada keamanan email dan tanda tangan digital. Algoritma ElGamal tebentuk melalui 3 proses yakni proses pembentukan kunci,proses enkripsi data dan proses dekripsi data.

Algoritma ini menggunakan chiper blok, adalah suatu proses enkripsi pada blok-blok chipertext. Kemudian pada blok-blok chipertext dilakukan proses dekripsi, dan hasilnya digabungkan agar menjadi suatu pesan yang utuh dan mudah dimengerti. Dalam pembentukan Algoritma kriptografi ElGamal, Diperlukan bilangan prima $p$ dan elemen primitif. ${ }^{[7]}$

Algoritma ElGamal memiliki public key berbentuk tiga pasang bilangan dan kunci rahasia berbentuk dua pasang bilangan. Algoritma ini memiliki kerugian terdapat pada pembentukan chipertext-nya yang memiliki ukuran dua kali lipat lebih besar dari pada plaintext-nya. Namun, Algoritma ElGamal miliki kelebihan pada proses enkripsi. Pada plaintext yang sama, algoritma ini menghasilkan chipertext yang berbeda-beda pada saat plaintext tersebut di enkripsi.

Hal tersebut disebabkan karena pengaruh dari suatu variabel yang ditetapkan secara acak saat proses enkripsi dilakukan. Pada Gambar 2.1 adalah diagram blok dari algoritma ElGamal. ${ }^{[6]}$

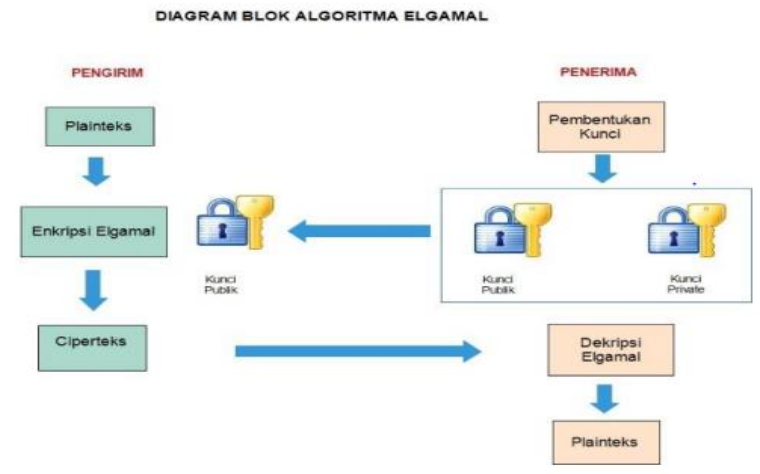

Gambar 2.1 Skema Diagram Blok Algoritma Elgamal

\subsection{Domain Parameter Kurva Eliptik}

Dalam pembahasan ini memuat tentang pembentukan domain parameter kurva eliptik atas $F_{p}$. Salah satu cara mengimplementasikan kriptografi kurva eliptik adalah dengan mempersiapkan parameter yang diperlukan oleh kriptosistem ElGamal. Domain parameter kurva eliptik atas $F_{p}$ yang memenuhi standar SEC 2 didefinisikan sebagai berikut ${ }^{[11]}$ :

$$
T=(p, a, b, G, n, h)
$$

Dimana:

$$
\begin{aligned}
& p \quad \text { : bilangan prima } \\
& \alpha, b: \text { koefisien persamaan kurva eliptik } \\
& G \quad \text { : titik dasar yaitu elemen pembangunan grup } \\
& \text { kurva eliptik } \\
& n \quad \text { : order dari } G \text { yaitu bilangan bulat positif } \\
& \text { terkecil } э \mathrm{n} . G=0 \\
& h \quad: \text { kofaktor, } h=\# E / n, \# E \text { adalah jumlah titik } \\
& \text { dalam grup Eliptik } \mathrm{E}_{\mathrm{p}}(\alpha, b)
\end{aligned}
$$

\subsection{Pembangkitan Kunci}

Berdasarkan parameter yang sesuai pada standarisasi SEC 2, sebagian dari parameter yang terbentuk digunakan untuk membangkitkan kunci publik dan kunci privat tersebut. Untuk membangkitkan kunci tersebut dapat memakai perhitungan $Q=d . G$ yang sesuai berdasarkan aturan kurva elitpik. Jika kunci tersebut telah dibangkitkan, langkah selanjutnya yaitu proses enkripsi dan dekripsi citra. Algoritma pembangkit kunci ElGamal melalui kurva eliptik yakni $^{[11]}$.

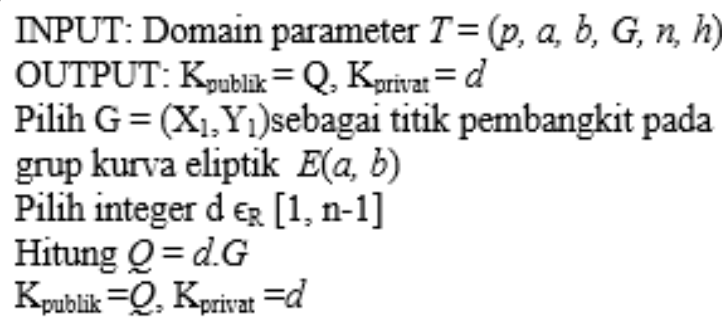

\subsection{Perancangan Sistem Enkripsi dan Dekripsi Citra}

Dalam perancangan sistem enkripsi dan dekripsi, citra awal yang berwarna RGB (Red Green Blue) akan dienkripsi denganmenggunakan algoritma ElGamal. Pertama dalam melakukan proses enkripsi yaitu dengan menentukan persamaan kurva eliptik $y^{2}=x^{3}+\alpha x+b \quad(\bmod p)$, dengan memasukkan nilai $a, b, \quad p$ untuk modulonya maka berdasarkan nilai tersebut dapat diperoleh beberapa titik - titik yang sesuai berdasarkan input yang dimasukkan. Nilai $a, b$, dan $p$ akan mempengaruhi $E\left(\mathrm{~F}_{\mathrm{p}}\right)$. Sesudah memperoleh beberapa titik tersebut, proses selanjutnya adalah mencari titik ketiga $\left(\mathrm{X}_{3}, \mathrm{Y}_{3}\right)$, dimana titik ketiga ini diperoleh berdasarkan proses untuk membuat suatu kurva eliptik, hasil dari titik ketiga ini dapat digunakan sebagai kunci publik. Kunci publik yang digunakan berasal dari SEC (Standards 
Efficient Cryptography) 2: Recommended Elliptic Cuve Domain Parameter.

Demikian juga untuk kunci privat yang digunakan berasal dari SEC 2. Setelah diperoleh kunci publik dan kunci privat dari SEC 2, selanjutnya memasukkan citra awal ke dalam sistem ini. Selanjutnya yaitu membangkitkan kunci (generate key), dimana kunci publik akan dikirim kepada penerima sedangkan kunci privat menjadi milik pribadi. Kemudian citra awal berwarna tersebut dibaca pixel-nya dalam bentuk plaintext. Setelah proses enkripsi citra awal tersebut berubah dan menghasilkan chipertext.

Citra awal $(M)$ sebagai masukkan algoritma enkripsi kriptosistem ElGamal dengan kurva eliptik. Pengenkripsi memilih secara acak integer $k$ dan menghitungnya. Berikut adalah algoritma yang digunakan dalam proses enkripsi ${ }^{[11]}$ :

INPUT : Domain parameter $T=(p, a, b, G, n, h)$, kunci publik $Q$, plaintext $\mathrm{M}$

Output: Chipertext C1,C2

Pilih $k \epsilon_{R}[1, n-1]$

Hitung $C_{l}=k . G$

$$
\text { Hitung } C 2=M+k \cdot Q
$$

Chipertext $\mathrm{Cl}, \mathrm{C2}$

Dalam perancangan sistem dekripsi, akan mengubah kembali bentuk citra awal dari bentuk chipertext ke dalam bentuk plaintext. Citra dalam bentuk chipertext tersebut kemudian dimasukkan kunci privat yang bersumber dari SEC 2. Selanjutnya dilakukan proses dekripsi citra untuk mengembalikan citra ke dalam bentuk plaintext. Kemudian dilakukan proses pembacaan citra menjadi pixel dan menjadi citra asli. Berikut adalah algoritma yang digunakan dalam proses dekripsi ${ }^{[11]}$ :

INPUT : Domain parameter $T=(p, a, b, G, n, h)$, kunci privat $d$, chipertext $(C 1, C 2)$ OUTPUT: plaintext $M$

Hitung $M=C 2-d . C l$ plaintext $\mathrm{M}$

\section{METODOLOGI PENELITIAN}

\subsection{Diagram Alur Penelitian}

Metodologi yang dipakai dalam penelitian ini menggunakan metodologi penelitian pengembangan (Research and Development). Metodologi penelitian dan pengembangan adalah suatu metode penelitian yang digunakan untuk menciptakan suatu produk tertentu seperti perangkat lunak, suatu alat dan komponen, dan menguji efektivitas dari produk yang telah dihasilkan tersebut. Pada gambar 3.1 adalah langkah-langkah penggunaan Metode R\&D.

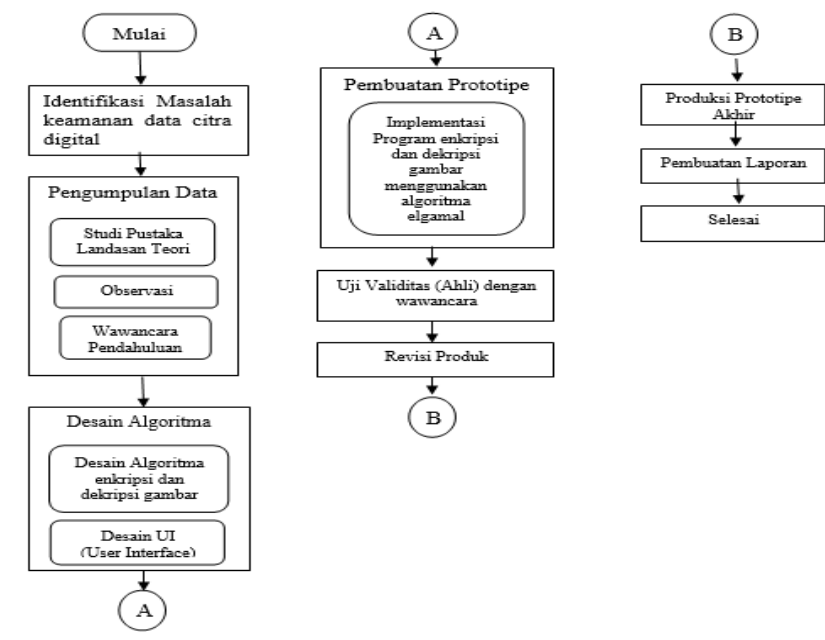

Gambar 3.1 Langkah - Langkah Penggunaan Metode R\&D

\subsection{Penjelasan Diagram Alur Metodologi Penelitian}

Dalam sub bab ini, penulis menjelaskan secara singkat mengenai diagram alir penelitian yang ditunjukan pada Gambar 3.1.

Pada Tahap Identifikasi Masalah Keamanan Data Citra Digital. Tahap ini akan mengidentifikasi masalah pada keamanan data citra yang ada di PT.Puninar Yusen Logistics Indonesia, serta masalah yang dihadapi oleh karyawan yaitu tentang keamanan data gambar yang ada di perusahaan. Dan dari masalah tersebut terdapat potensi apa yang dapat dikembangkan untuk mengatasi masalah yang ada.

Pada tahap pengumpulan data, penulis menggunakan beberapa metode atau teknik yang digunakan dalam mengumpulkan data. Adapun metode yang digunakan penulis dalam pengumpulan data adalah:

a. Studi Pustaka Landasan Teori

Penulis mengumpulkan data-data menggunakan buku dan jurnal yang berhubungan dengan penelitian.

b. Observasi

Metode ini dilakukan dengan mengamati dan melihat langsung Aplikasi keamanan data yang digunakan di PT.Puninar Yusen Logistics Indonesia.

c. Wawancara Pendahuluan

Sebuah proses tanya-jawab yang dilakukan secara langsung dengan lisan yang ditunjukan kepada Kepala Departemen IT dari PT Puninar Yusen Logistics Indonesia, bertujuan untuk menentukan apakah Aplikasi keamanan data yang penulis ajukan sekiranya cocok dan dapat di terapkan di PT.Puninar Yusen Logistics Indonesia.

Pada Tahap Desain Algoritma, penulis melakukan desain algoritma enkripsi dan dekripsi gambar untuk bagian komponen utama dalam pembuatan aplikasi enkripsi dan dekripsi menggunakan algoritma ElGamal. Dan desain User Interface untuk memberikan gambaran tentang sistem yang akan dibangun dan hasilnya sesuai dengan kebutuhan. Dengan memperhatikan desain tampilan 
sehingga mempermudah pengguna dalam menggunakan aplikasi ini.

Pada Tahap Pembuatan Prototipe, penulis melakukan implementasi program enkripsi dan dekripsi gambar menggunakan algoritma ElGamal. Desain yang sebelumnya dirancang diimplementasikan pada sebuah aplikasi berbasis mobile Android Studio yang digunakan dalam pembuatan aplikasi ini. Dilakukan juga tahap validasi produk yang dilakukan oleh narasumber yang sudah berpengalaman untuk menilai aplikasi yang sudah dirancang tersebut. Validasi dilakukan untuk mengetahui kelemahan dan kelebihan aplikasi untuk diperbaiki.

Setelah melakukan validasi pembuatan produksi prototipe akhir Aplikasi enkripsi dan dekripsi gambar menggunakan algoritma ElGamal dilakukan.

Pada Tahap pembuatan laporan penulis menjelaskan secara keseluruhan penelitian yang telah dirancang dan diuji.

\section{HASIL DAN PEMBAHASAN}

Sistem akan diuji untuk mengetahui apakah proses enkripsi dan dekripsi citra dapat berjalan dengan baik. Pada penelitian ini, aplikasi dibuat pada perangkat mobile dengan sistem operasi Android menggunakan bahasa pemrograman Java. Software yang digunakan adalah Android Studio. Format gambar yang diuji adalah .jpg, .bmp, .png, dan .gif dengan resolusi maksimal 1500x1500 pixel Aplikasi ini memiliki 4 halaman, yaitu : Home, Generate Key, Enkripsi, dan Dekripsi.

\subsection{Interface Halaman Home}

Interface halaman Home dapat dilihat pada gambar 4.1.

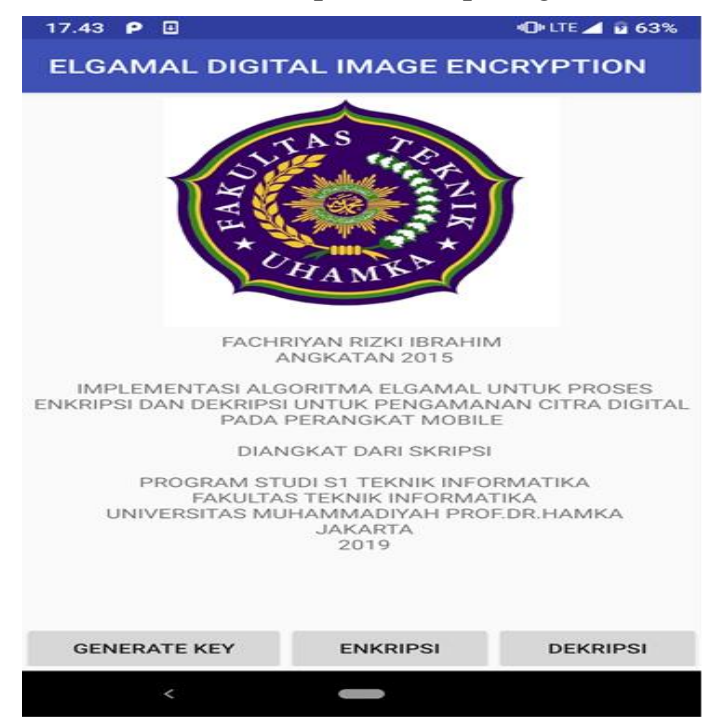

Gambar 4.1 Interface Halaman Home

Halaman Home merupakan halaman utama yang berisikan judul aplikasi, logo universitas, identitas pembuat aplikasi , tombol generate key, enkripsi, dan dekripsi.

\subsection{Interface Halaman Generate Key}

Interface halaman Generate Key dapat dilihat pada gambar 4.2.

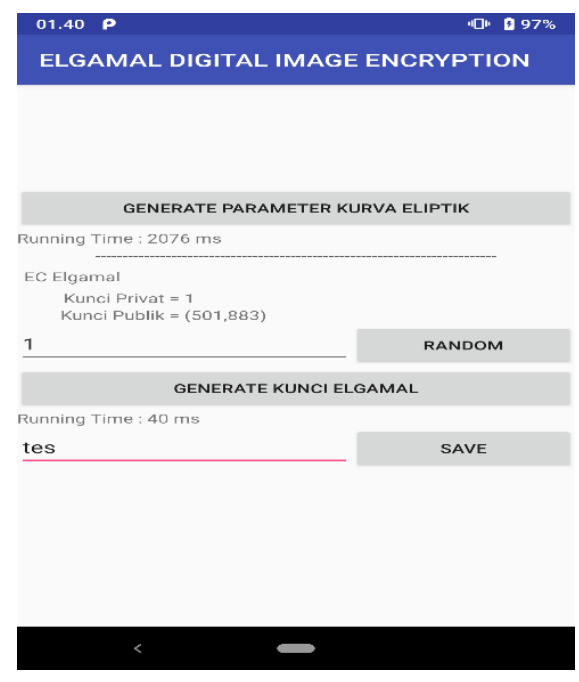

Gambar 4.2 Interface halaman Generate Key

Halaman Generate Key merupakan halaman yang memuat proses pembangkitan kunci publik dan kunci privat yang akan digunakan untuk melakukan proses enkripsi dan dekripsi. Proses pada halaman ini akan membentuk suatu parameter kurva eliptik, yaitu parameter yang dihasilkan untuk membentuk kunci publik algoritma ElGamal. Untuk kunci privat pengguna bisa langsung menentukan nilai yang diinginkan atau menentukan nilai secara acak dengan tombol random.

Setelah selesai menentukan nilai untuk kunci privat dan kunci publik pengguna menekan tombol Generate Kunci ElGamal, dan memasukkan nama untuk kunci privat dan kunci publik. Setelah selesai pengguna menekan tombol save untuk menyimpan kunci publik dan kunci privat yang telah di input.

Setelah itu akan keluar notifikasi yang menyatakan proses generate key selesai. Tampilan notifikasi proses generate key selesai dapat dilihat pada gambar 4.3

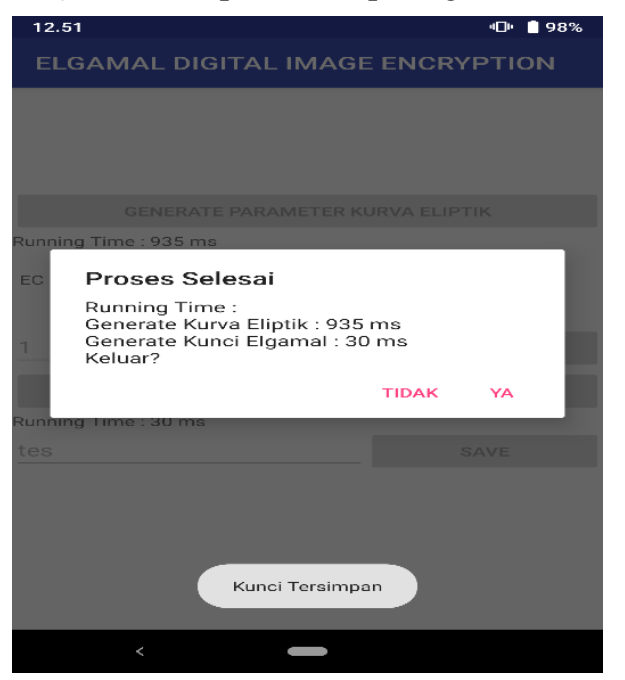

Gambar 4.3 Notifikasi Proses Generate Key Selesai

Pada notifikasi proses generate key terdapat keterangan Real Running Time yang merupakan lama 
waktu untuk pembuatan kurva eliptik dan kunci algoritma ElGamal.

Setelah notifikasi telah ditampilkan dan kunci telah dibuat maka secara otomatis kunci yang telah dibuat akan tersimpan di memory internal smartphone dengan nama folder "Skripsi". Tampilan folder penyimpanan kunci dapat dilihat pada gambar 4.4

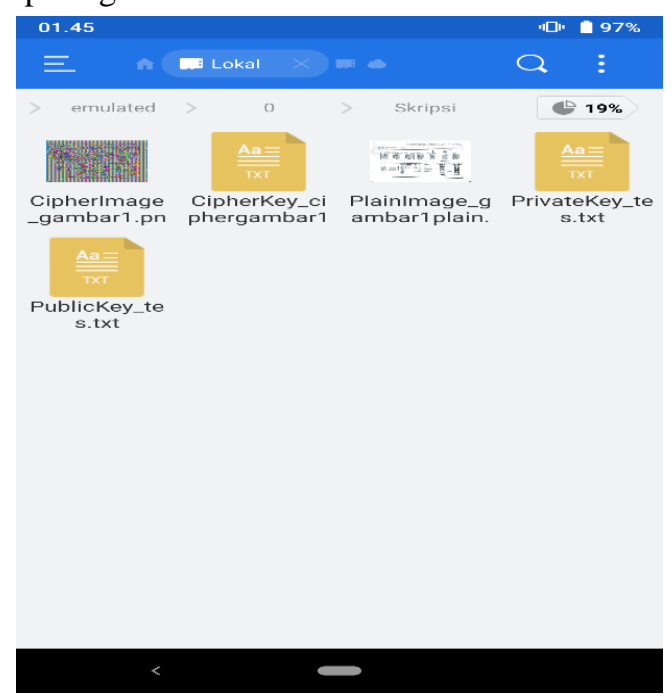

Gambar 4.4 Folder Penyimpanan Kunci

Pada folder penyimpanan kunci terdapat kunci privat, kunci publik, chiperkey, cipherimage dan plainimage.

\subsection{Interface Halaman Enkripsi}

Interface halaman sebelum citra dienkripsi dapat dilihat pada gambar 4.5.

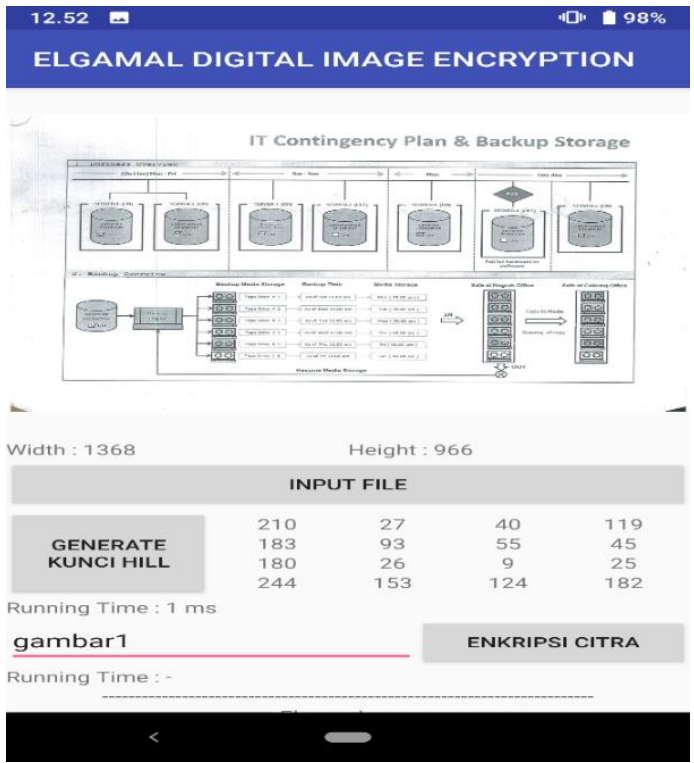

Gambar 4.5 Tampilan Sebelum Citra Dienkripsi

Halaman enkripsi merupakan halaman yang memuat proses pengenkripsian citra digital. Di halaman ini file citra dan kunci Hill Cipher dienkripsi. Citra digital dienkripsi menjadi cipherimage dan kunci Hill Cipher dienkripsi menjadi cipherkey. Citra dienkripsi menggunakan kunci dari Hill Cipher, lalu kunci dari Hill Cipher tersebut dienkripsi menggunakan kunci publik yang telah dibangkitkan pada halaman Generate Key dengan algoritma ElGamal. Pengguna lalu memasukkan nama yang akan digunakan untuk cipherimage dan menekan tombol enkripsi citra.

Sedangkan untuk Interface setelah citra di enkripsi dapat dilihat pada gambar 4.6.

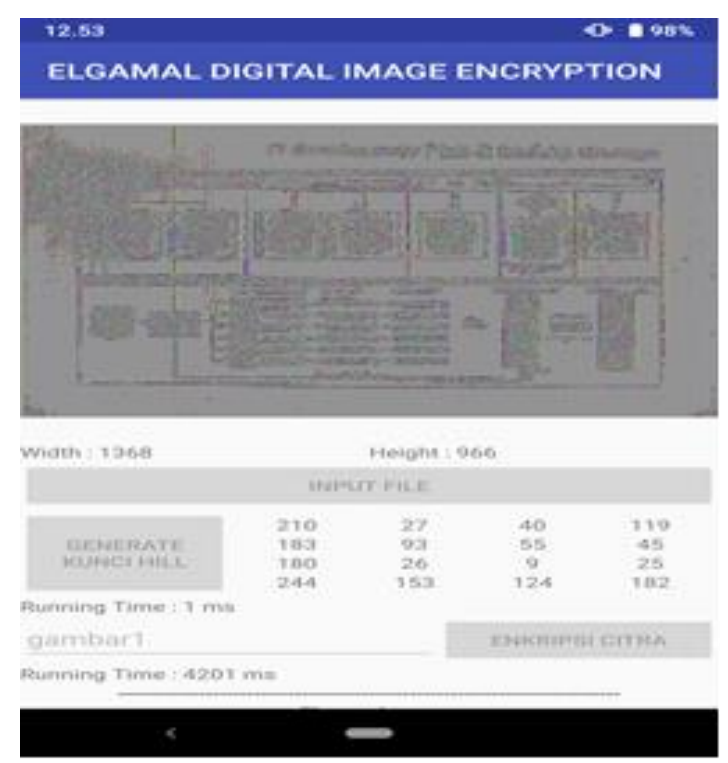

Gambar 4.6 Interface Setelah Citra Dienkripsi

Pada gambar 4.6 citra awal yang masih utuh dienkripsi menjadi cipherimage agar informasi di dalam citra tersebut tidak dapat dilihat.

Tampilan halaman enkripsi dapat dilihat pada gambar 4.7

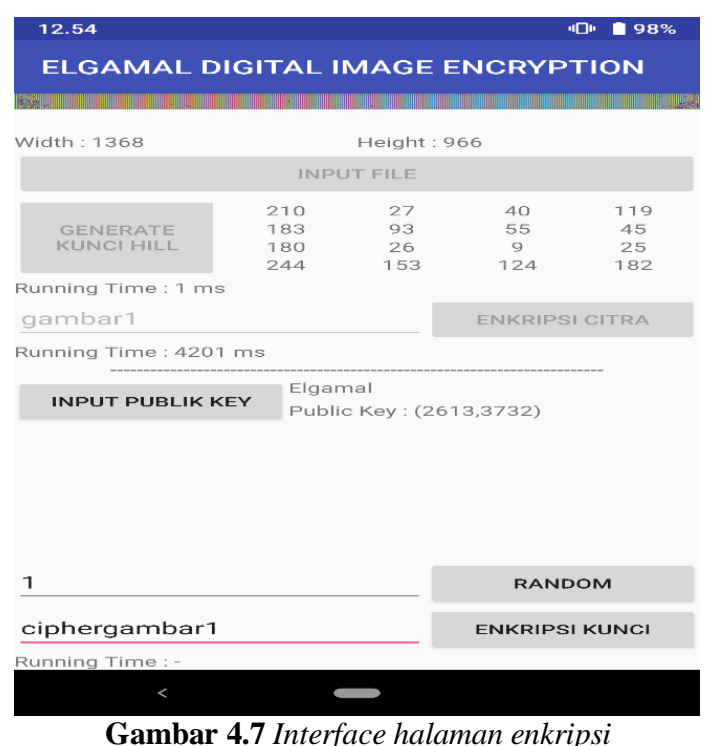

Setelah citra telah berhasil di enkripsi pengguna menekan tombol Input publik Key dan memasukkan kunci publik yang telah tersimpan pada folder skripsi. Pengguna lalu dapat menentukan bilangan acak $r$ dengan memasukkan nilai yang diinginkan atau menentukan nilai secara acak dengan menekan tombol random. Setelah bilangan acak $r$ di tentukan makan penggun dapat memasukkan nama yang digunakan untuk cipherkey dengan menekan tombol enkripsi kunci. Sistem akan menampilkan notifikasi proses 
selesai dan menampilkan Running Time dari Generate matriks, Enkripsi Citra, dan Enkrips Kunci. File cipherimage dan cipherkey yang telah dibuat tersimpan didalam folder "Skripsi".

\subsection{Interface Halaman Dekripsi}

Interface halaman dekripsi dapat dilihat pada gambar 4.8.

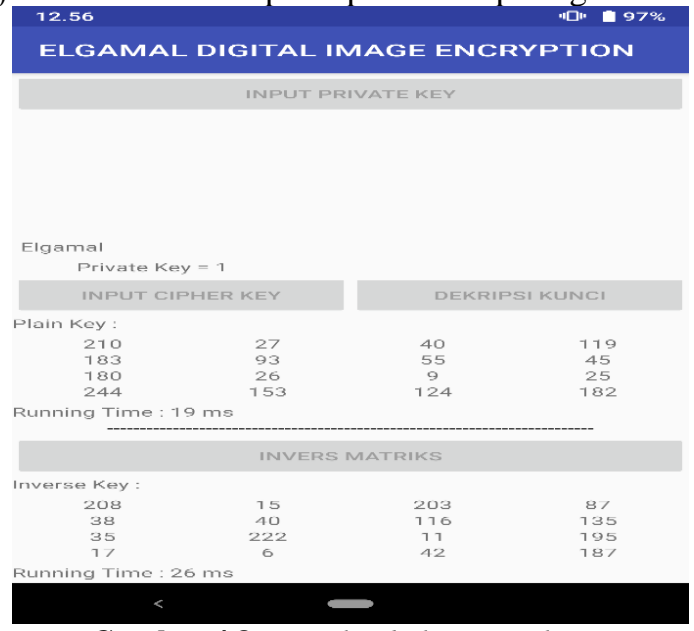

Gambar 4.8 Tampilan halaman Dekripsi

Halaman dekripsi merupakan halaman yang memuat proses pendekripsian citra digital. Pada halaman ini kunci privat dan cipherkey diinputkan. Pengguna menekan tombol Dekripsi Kunci, kemudian cipherkey didekripsi menjadi plain key menggunakan kunci privat dengan algoritma ElGamal. Lalu pengguna menekan tombol Invers Matriks kemudian plain key yang telah didapat dicari invers matriks dari plain key, yang kemudian digunakan untuk mendekripsi cipherimage menjadi plainimage atau citra awal.

Tampilan sebelum citra didekripsi dapat dilihat pada gambar 4.9.
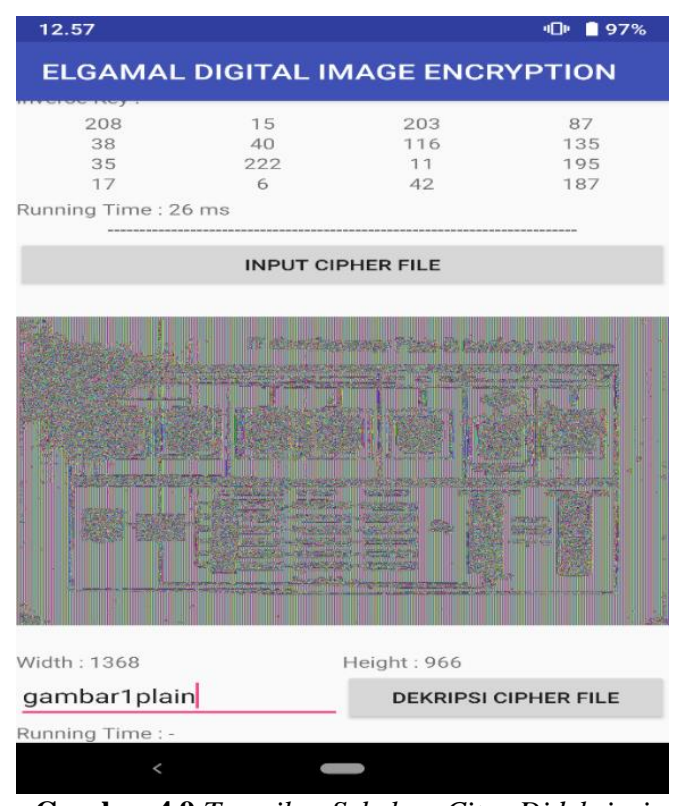

Gambar 4.9 Tampilan Sebelum Citra Didekripsi

Setelah invers matriks dari plainkey didapatkan pengguna menekan tombol Input Cipher File lalu pengguna memasukkan cipherimage yang telah disimpan pad folder Skripsi. Kemudian pengguna memasukkan nama yang akan digunakan untuk plainimage atau citra awal. Setelah nama dimasukkan pengguna lalu menekan tombol Dekripsi Cipher File, dan Cipherimage akan didekripsi menjadi plainimage.

Tampilan setelah citra didekripsi dapat dilihat pada gambar 4.10.

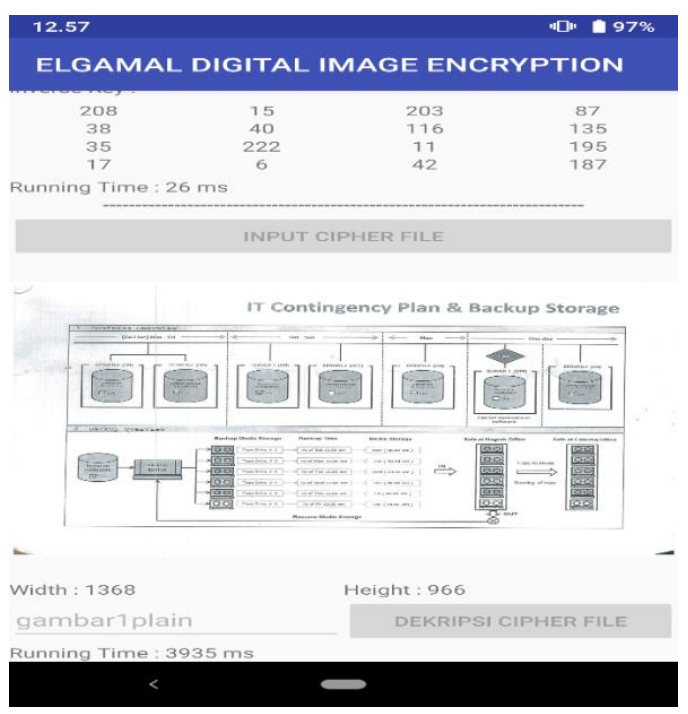

Gambar 4.10 Tampilan Setelah Citra Didekripsi

Pada gambar 4.10 adalah tampilan setelah citra didekripsi. Citra yang sebelumnya dienkripsi dan berubah menjadi cipherimage didekripsi agar citra tersebut kembali ke bentuk awal dan informasi didalam citra tersebut bisa terlihat.

\subsection{Pengujian Aplikasi}

Pengujian aplikasi yang dilakukan menggunakan metode black box untuk memeriksa apakah setiap komponen yang telah dibuat di dalam sistem telah bekerja dan proses sistem ini dapat dilihat pada tabel 4.1.

Tabel 4.1(a) Tabel pengujian Aplikas ElGamal Digital Encryption

\begin{tabular}{|c|c|c|c|}
\hline Menu yang diuid & Penguiian & Hasil & Keterangan \\
\hline \multirow{4}{*}{ Home } & Memilih button & $\begin{array}{c}\text { Button dapat di klik dan } \\
\text { berpindah scene sesuai } \\
\text { nama button. }\end{array}$ & Berhasil \\
\hline \multirow{5}{*}{ Generate Key } & $\begin{array}{c}\text { Membangkitkan } \\
\text { parameter kurva } \\
\text { eliptik }\end{array}$ & $\begin{array}{c}\text { Parameter kurva eliptik } \\
\text { dapat dibangkitkan dan } \\
\text { sistem dapat menampilkan } \\
\text { Real Running Time saat } \\
\text { para meter dibangkitkan }\end{array}$ & Berhasil \\
\cline { 2 - 4 } & Kundom & $\begin{array}{c}\text { Sistem dapat menentukan } \\
\text { angka secara acak }\end{array}$ & Berhasil \\
\cline { 2 - 5 } & Kembangkitkan & $\begin{array}{c}\text { Kunci publik dan kunci } \\
\text { privat ElGamal dapat } \\
\text { dibangkitkan }\end{array}$ & Berhasil \\
\cline { 2 - 5 } & Save & $\begin{array}{c}\text { Sistem dapat menyimpan } \\
\text { kunci ElGamal yang telah } \\
\text { dibangkitkan dan dapat } \\
\text { menampilkan notifikasi } \\
\text { proses generate key selesai }\end{array}$ & Berhasil \\
\cline { 2 - 5 } & $\begin{array}{c}\text { Setelah kunci tersimpan } \\
\text { dan notifikasi ditampilkan } \\
\text { muncul opsi keluar, dan } \\
\text { ketika di klik dapat } \\
\text { kembali ke menu Home }\end{array}$ & Berhasil \\
\hline
\end{tabular}


Tabel 4.1(b) Tabel pengujian Aplikasi ElGamal Digital Encryption

\begin{tabular}{|c|c|c|c|}
\hline Menu yang diuii & Penguiian & Hasil & Keterangan \\
\hline \multirow{7}{*}{ Enkripsi } & Input File & $\begin{array}{c}\text { Sistem dapat menerima } \\
\text { masukkan berupa file citra } \\
\text { digital dengan ekstensi .jpg, } \\
\text {.png, .bmp, dan .gif dengan } \\
\text { resolusi maksimal } \\
1500 \times 1500 \text { pixel } \\
\end{array}$ & Berhasil \\
\hline & Generate Hill & $\begin{array}{l}\text { Sistem dapat membangkitkan } \\
\text { kunci hill dengan matriks } \\
\text { angka secara random }\end{array}$ & Berhasil \\
\hline & Enkripsi Citra & $\begin{array}{c}\text { Sistem dapat mengenkripsi } \\
\text { citra yang di input menjadi } \\
\text { cipherimage }\end{array}$ & Berhasil \\
\hline & $\begin{array}{c}\text { Input Publik } \\
\text { Key }\end{array}$ & $\begin{array}{c}\text { Sistem dapat membaca } \\
\text { masukan berupa kunci publik } \\
\text { E1Gamal }\end{array}$ & Berhasil \\
\hline & Random & $\begin{array}{l}\text { Sistem dapat menentukan } \\
\text { angka secara acak }\end{array}$ & Berhasil \\
\hline & Enkripsi Kunci & $\begin{array}{l}\text { Sistem dapat melakukan } \\
\text { penyimpanan file } \\
\text { cipherimage dan cipherkey } \\
\text { yang telah dibuat serta dapat } \\
\text { menampilkan notifikasi } \\
\text { proses enkripsi selesai }\end{array}$ & Berhasil \\
\hline & Pindah scene & $\begin{array}{l}\text { Setelah kunci tersimpan dan } \\
\text { notifikasi ditampilkan } \\
\text { muncul opsi keluar, dan } \\
\text { ketika di klik dapat kembali } \\
\text { ke menu Home }\end{array}$ & Berhasil \\
\hline
\end{tabular}

Tabel 4.2(c) Tabel pengujian Aplikasi ElGamal Digital Encryption

\begin{tabular}{|c|c|c|c|}
\hline Menu yang diuii & Pengujian & Hasil & Keterangan \\
\hline \multirow{7}{*}{ Dekripsi } & $\begin{array}{c}\text { Input Private } \\
\text { Key }\end{array}$ & $\begin{array}{l}\text { Sistem dapat menerima } \\
\text { masukkan berupa file kunci } \\
\text { privat yang telah dibuat }\end{array}$ & Berhasil \\
\hline & $\begin{array}{c}\text { Input Cipher } \\
\text { Key }\end{array}$ & $\begin{array}{l}\text { Sistem dapat menerima } \\
\text { masukkan berupa file } \\
\text { cipherkey yang telah dibuat }\end{array}$ & Berhasil \\
\hline & Dekripsi Kunci & $\begin{array}{l}\text { Sistem dapat melakukan } \\
\text { proses dekripsi kunci dan } \\
\text { menampilkan plainkey dari } \\
\text { cipherkey yang telah dibuat }\end{array}$ & Berhasil \\
\hline & Invers Matriks & $\begin{array}{l}\text { Sistem dapat melakukan } \\
\text { proses invers matriks dari } \\
\text { plainkey yang telah } \\
\text { ditampilkan }\end{array}$ & Berhasil \\
\hline & $\begin{array}{c}\text { Input Cipher } \\
\text { File }\end{array}$ & $\begin{array}{c}\text { Sistem dapat menerima dan } \\
\text { menampilkan masukkan } \\
\text { berupa file cipherimage yang } \\
\text { telah dibuat }\end{array}$ & Berhasil \\
\hline & $\begin{array}{c}\text { Dekripsi Cipher } \\
\text { File }\end{array}$ & $\begin{array}{c}\text { Sistem dapat melakukan } \\
\text { proses pendekripsian file } \\
\text { cipherimage menjadi } \\
\text { plainimage dan menampilkan } \\
\text { notifikasi proses dekripsi } \\
\text { selesai } \\
\end{array}$ & Berhasil \\
\hline & Pindah scene & $\begin{array}{c}\text { Setelah citra berhasil } \\
\text { didekripsi muncul opsi } \\
\text { keluar, dan ketika di klik } \\
\text { dapat kembali ke menu } \\
\text { Home }\end{array}$ & Berhasil \\
\hline
\end{tabular}

\section{SIMPULAN}

Berdasarkan hasil dari penelitian ini, didapatkan kesimpulan bahwa:

1. Pengamanan Citra digital dilakukan dengan menggunakan Algoritma ElGamal dengan menggabungkan dua buah kunci yaitu kunci publik dan kunci privat.

2. Citra digital yang dapat dienkripsi adalah citra digital dengan format .jpg, .bmp, .png, dan .gif dengan resolusi maksimal $1500 \times 1500$ pixel.

3. Algoritma ElGamal dapat diimplementasikan dan diterapkan dalam pengamanan citra digital untuk perangkat mobile.

\section{KEPUSTAKAAN}

[1] Triase, Kriptografi Elgamal Menggunakan Metode Mersenne, Jurnal Ilmiah Integritas Volume I, No.4:2-3, Desember 2015.

[2] Mukhtar, Harun, Kriptografi Untuk Keamanan Data, Yogyakarta: Deepublish, 2018.

[3] Irawati, Indrarini Dyah, Jaringan Komputer dan Data Lanjut, Yogyakarta: Deepublish, 2018.

[4] Rusri Yanti, Neti, Implementasi Algoritma Data Encryption Standard pada penyandian Record Database, Jurnal Sains \& Informatika Volume II, No.1:23-32, Maret 2018.

[5] Chandra, Keamanan Data Dengan Metode Kriptografi Kunci Publik, Jurnal TIMES Volume V, No.2:11-15, 2016.

[6] Widarma, Andi, Kombinasi Algoritma AES, RC4 dan ElGamal Dalam Skema Hybird Untuk Keamanan Data, CESS (Journal Of Computer Engineering System And Science) Volume I, No.1:1-8, Januari 2016.

[7] Agung Bagus, I Gusti, Sianipar Rismon H, dan Wiryajati, I Ketut., Teknik Steganografi Menggunakan Transformasi Slant Dengan Algoritma Enkripsi Elgamal, Dielektrika Volume I, No.1:6-15, Februari 2014.

[8] Enterprise, Jubilee, Java Untuk Pemula, Jakarta: PT Elex Media Komputindo, 2014

[9] Suryana, Dayat, Belajar Android Studio, Bandung: Dayat Suryana Independent, 2018.

[10] Supriyanto, Implementasi Hill Cipher pada Citra Menggunakan Koefisien Binomial Sebagai Matriks Kunci, Seminar Nasional Informatika, No.1:284-291, November 2015.

[11] Budi Utomo Daryono, Winda Setyawati Dian, dan Romadhoni F.R Gestihayu, Kriptografi Eliptik ElGamal Untuk Proses Enkripsi-Dekripsi Citra Digital berwarna, Seminar Nasional Matematika Volume I, No.1:373-383. 2014.

[12] Pudjo Widodo Prabowo, Menggunakan UML, Bandung:Informatika, 2012.

[13] Parmadi, Binantara, Implementasi Algoritma Kriptografi ElGamal pada data Text, Journal of Information and Technology Volume V, No.1:1-5, Juni 2017.

[14] Taufiq Tamam, M. , Dwiono Wakhyu, Hartanto Tri, Penerapan Algoritma Kriptografi ElGamal Untuk pengamanan file citra, Jurnal EECCIS Volume I, No.1:8-11, Juni 2010. 